\title{
Distribución de Hongos Medicinales en las Macro Regiones Pacífico y Centro de Nicaragua, 2006 - 2011
}

Noé Ubau Matamoros

Facultad de Ciencias e Ingeniería, Universidad Nacional Autónoma de Nicaragua, Managua

kronosneon@hotmali.com; gila.2008@yahoo.com

Recibido: enero 2012. Aprobado: agosto 2016

\section{RESUMEN}

La presente investigación muestra la distribución de siete especies de hongos medicinales Auricularia auricula, Ganoderlma lucidum, Ganoderma applanatum, Geastrum triplex, Pycnoporus sanguineus, Trametes versicolor y Schizophyllum commune en las Macro Regiones Ecológicas Pacífico y Centro nicaragüense y uso actual, aporte importante a la micología nacional. El estudio de visión retrospectiva muestra los sitios visitados en un periodo de 5 años que incluyen zonas Urbanas y Rurales, bosque Nuboso, bosque lluvioso, bosque Seco y bosque Ripario. El uso es determinado por investigación bibliográfica de autores enfocados en el estudio exclusivo de estos organismos.

Palabras Claves: Distribución; Hongos medicinales; Aplicaciones; Tratamiento y Prevención del Cáncer; Tratamiento del SIDA, Sarcomas; Suplemento Nutricional.

\section{ABSTRACT}

The present research shows the distribution of seven species of medicinal fungi Auricularia auricula, Ganoderma lucidum, Ganoderma applanatum, Geastrum triplex, Pycnoporus sanguineus, Trametes versicolor and Schizophyllum commune in the Pacific and Nicaraguan Ecological Macro Regions and current use, an important contribution to the Mycology. The retrospective study shows the sites visited in a 5 year period that include urban and rural areas, cloud forest, rainforest, dry forest and Ripario forest. The use is determined by bibliographical research of authors focused on the exclusive study of these organisms.

Key Words: Distribution; Medicinal mushrooms; Applications; Treatment and Prevention of Cancer; Treatment of AIDS, Sarcomas; Nutritional supplement.

\section{INTRODUCCIÓN}

En Nicaragua no existe una cultura micológica, es decir, el consumo de hongos como base de alimenticia y alternativa medicinal, en contraste con los vecinos del norte de la región Mesoamericana que persiste la costumbre en su sociedad, por tanto el conocimiento sobre los hongos es limitado. Como objetivo se pretende enriquecer los conocimientos generales y populares micológicos del país, enfatizando en sus usos y distribución.

Las especies Auricularia auricula, Ganoderlma lucidum, Ganoderma applanatum, Geastrum triplex, Pycnoporus sanguineus, Trametes versicolor y Schizophyllum commune, son hongos macroscópicos, en su mayoría saprófagos pertenecientes a los Basidiomycotas. Muchas especies de 
hongos se logran encontrar en bosques de las regiones tropicales y subtropicales de América, África, Asia y Australia (FAO, 2008).

Las especies de hongos antes mencionadas se consideran medicinal y alto valor en países asiáticos y en comunidades indígenas de América Latina. Debido a que contienen componentes activos, proteínas y minerales de importancia para el desarrollo humano, tratamiento y prevención de enfermedades de interés humano.

\section{MATERIAL Y MÉTODOS}

\section{Áreas de Estudio}

Reserva Natural Estero Real-Padre Ramos, Reserva Privada Monti Belli-Ticuantepe, Reserva Natural Volcán Maderas-Ometepe, Finca Nuevo Amanecer-San Ramón, Reserva Privada Fundación Esperanza Verde-Rio San Juan, El Castillo y San Carlos - Rio San Juan, Km 15 - El Crucero, UNANManagua, Finca El Nisperal - La Concepción (Concha), Macizo de Peñas Blanca y Cerro Arenal Matagalpa, Juigalpa-Chontales, Cerro Kilambe Wiwilí - Jinotega.

\section{Tipo de Estudio}

El estudio es descriptivo de corte transversal, de carácter retrospectivo, basados en una compilación de cinco años de viajes por el centro y pacífico de Nicaragua; la información sobre los hongos medicinales es el resultado de investigaciones bibliográficas de los estudios practicados en diferentes países a las diferentes especies objeto de estudio.

\section{Áreas de Muestreo}

Las áreas de muestreos incluyen zonas Urbanas y Rurales, bosque Nuboso, bosque Lluvioso, bosque Seco y bosque Ripario.

\section{Variables}

\begin{tabular}{|c|c|c|}
\hline Variable & Indicador & Tipo de Variable \\
\hline Olor & Frutos secos, carnes, ajo, fenol, anís, heces fecales & \multirow{2}{*}{} \\
\hline Sabor & Anís, frutos secos, carnes, picantes, amargo \\
\hline Distribución & Macroregiones territoriales & \multirow{2}{*}{ Cualitativas } \\
\hline Descripción Morfológica & Macroscópica y microscópica \\
\hline Habitad & Bosque y climas & \\
\hline Hábitos & Saprófago, humícola, coprófago, lignícola, folícola \\
& & \\
\hline
\end{tabular}




\section{Colecta de Hongos:}

Los especímenes fueron fotografiados en el medio natural, posteriormente introducidos en bolsas de papel, para el traslado a los laboratorios del Departamento de Biología. Las colectas se encuentra almacenadas en el Herbario del Departamento de Biología de la UNAN - Managua.

\section{Descripción e identificación de Especies}

\section{Descripción Macroscópica}

Poniendo en práctica la metodología convencional para el manejo de Macrohongos, se procedió a la anotación de características morfológicas externas e internas en una tabla. Las caracteres consideradas son Píleo (sombrero), Himenio, Contexto, Estípite, Pié y dimensiones de las estructuras antes mencionadas. Posteriormente se hizo uso de claves dicotómicas para la ubicación taxonómicas de las especies.

\section{Descripción Microscópica}

Se realizaron montajes de las estructuras reproductivas, sean láminas, tubos, poros, etc. para la observación y descripción de esporas y estructura reproductivas. El uso de reactivo facilitó la observación de las estructuras bajo el microscopio. Tales reactivos son Ácido Nítrico al 3\%, Amoniaco al 5\%, Lugol, Azul de Metileno, KOH 10\% (Hidroxido de Potasio).

\section{Equipos de Laboratorio}

- Guantes de látex,

- Tapa boca

- Microscopio

- Bisturí

- Pinzas

- Micrótomo manual.

\section{RESULTADOS}

Se identificaron 7 especies de hongos de carácter medicinal, distribuidas en 11 departamentos del centro y pacífico de Nicaragua. Las especies de hongos más comunes durante todo el año son Pycnoporus sanguineus, Trametes versicolor y Schizophyllum commune, de amplia distribución. 
Auricularia auircula, de amplia distribución, encontrándose en la región pacífica y central durante la estación lluviosa, en Rio San Juan y en bosque nuboso todo el año.

La especie Ganoderma lucidum, tiene une una distribución limitada, desde el sur en Rio San Juan hasta Managua, en contra posición de la especie Ganoderma applanatum, que se distribuye desde la Región Nor-Central en Matagalpa hasta Managua; la distribución de ambas especies converge en Managua, de igual manera su aparición coinciden a inicio de la estación lluviosa a febrero en G lucidum y enero en G. applanatum.

Geastrum triplex, solamente se ha encontrado en los departamentos de Carazo, Managua y Masaya, durante la estación lluviosa, en pendientes entre $45^{\circ}$ a $60^{\circ}$, fructificando después de sucedida las escorrentías.

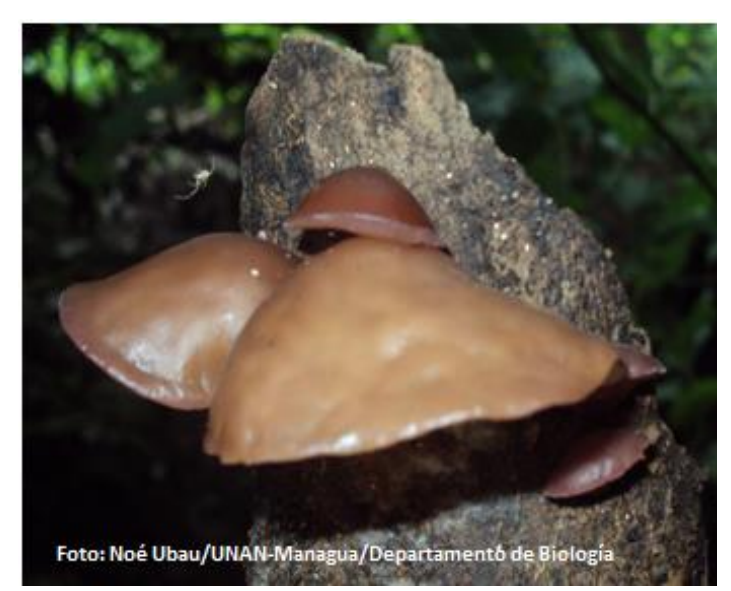

Figura 1. Auricularia auricula (Bull.) Westtstein

\section{Auricularia auricula (Bull.) Westtstein}

Distribución: Localizado en áreas húmedas y en microclimas húmedos en regiones secas del país. Se extendiéndose por toda la vertiente del Pacífico y Centro del País. A. aricula es una especie versátil de amplia distribución con grandes posibilidades que se encuentre en las regiones autónomas del Caribe (Anexo1). Altura: 16 msnm a 1300 msnm. Estacionalidad: Generalmente Junio a Diciembre.

Descripción: Cuerpo fructífero1 en forma de oreja, de textura carnosa a caucho, de color naranja pardusco, de tamaño variado desde $3.0 \mathrm{~cm}$ a 5.0 cm de largo, hasta $15.0 \mathrm{~cm}$ a $29.4 \mathrm{~cm}$ de largo; cutis liso a aterciopelado; himenóforo2 liso y del mismo color del cutis; contexto del mismo color que la superficie, de consistencia gelatinosa, de 0.7 cm a 1.9 cm de espesor; Textura corácea. Reproducción: Por medio de esporas. Esporada: No anotada.

Hábitat: Suele desarrollarse en madera en descomposición y postes de cercos. Hábitos: Saprófago, generalmente se encuentra agrupado y unidos por la base, a veces solitario.

Propiedades: A. Ríos describe a A. auricula como un potencial nutricional y medicinal, y concluye que presenta compuesto bioactivos como esteroides, triterpenoides y quinonas que pueden tener aplicabilidad terapéuticas en enfermedades de origen respiratorio y circulatorio. 
Tabla 1. Componente minerales y nutricionales de A. aurícula

\begin{tabular}{|l|l|l|l|}
\hline \multicolumn{2}{|c|}{ Com. Mayores \% } & \multicolumn{2}{c|}{ Microelementos (p.p.m) } \\
\hline Humedad & 92,43 & Sodio & 701.00 \\
Proteínas & 9.25 & Hierro & 254.00 \\
Grasas & 0.41 & Boro & 52.00 \\
Carbohidratos & 47.32 & Manganeso & 32.00 \\
Cenizas & 3.36 & Cobre & 3.00 \\
\hline Macroelemente \% & \multicolumn{3}{|}{ Vitaminas (mg) } \\
\hline Zinc & $20 \%$ & Nicotinamida & 38.12 \\
Potasio & 0.81 & Tiamina & 17.03 \\
Fósforo & 0.16 & Piridoxina & 1.62 \\
Calcio & 0.16 & Vitamina C & 2.2 \\
Magnesio & 0.16 & & \\
Azufre & 0.03 & & \\
\hline
\end{tabular}

\section{Ganoderma lucidum (Leyss. Ex. Fr.) Karst.}

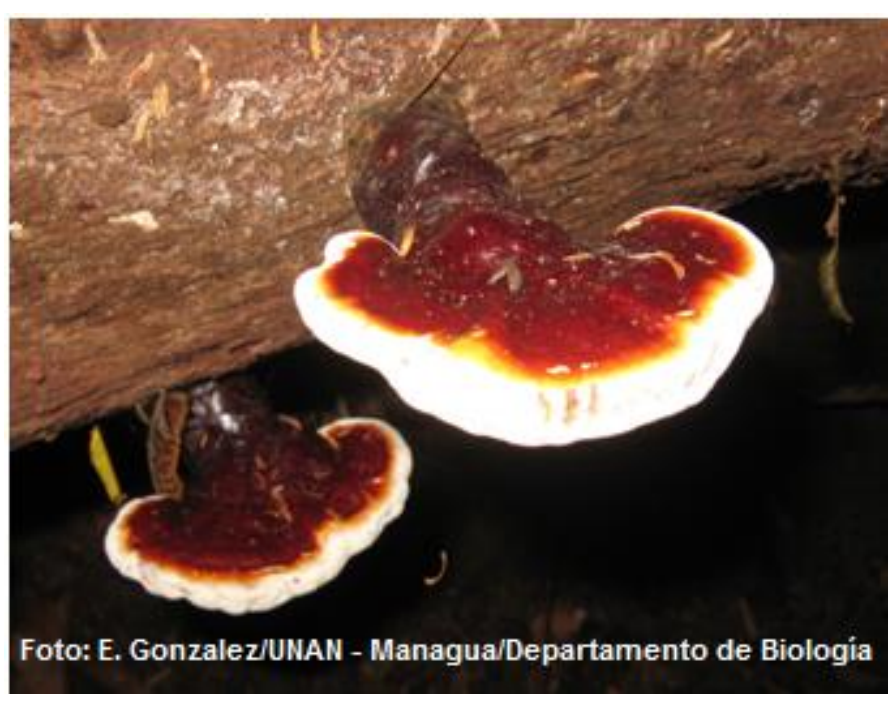

Figura 2. G. lucidum en medio natural. Ganoderma lucidum (Leyss. Ex. Fr.) Karst.
Distribución: Se puede encontrar en regiones húmedas en bosques de Río San Juan, bosques secos de Managua y áreas urbanas de la capital (UNAN Managua) (Anexo1). Altura: Desde 30 msnm a 400 msnm. Estacionalidad: De finales de Mayo a Febrero

Descripción: Cuerpo fructífero en forma espatulada a copa; estipitado, céntrico o marginal, a veces ausente; Píelo de $15.0 \mathrm{~cm}$ a $30.0 \mathrm{~cm}$ diámetro, de cutis rojo, seroso al contacto, presentando zonaciones concéntricas, margen convexo y seroso, a veces blanco y esponjoso; Himenóforo de color blanco a gris a blanco, formado por tubos de $0.5 \mathrm{~cm}$ a $1.0 \mathrm{~cm}$ de largo y 0.05 de ancho. Contexto color marrón claro, de $2.0 \mathrm{~cm}$ a $5.1 \mathrm{~cm}$ de espesor, de aspecto fibroso y sedoso al tacto, tubos color marrón oscuro; Estípite color rojo, de $5.0 \mathrm{~cm}$ a $10.0 \mathrm{~cm}$ de largo, de textura serosa y quebradizo, en forma de clavo. Reproducción: Por medio de esporas; esporada color marrón oscuro.

Habitad: En el bosque suele encontrarse adherido a raíces de árboles y tocones de árboles recién cortados, en centros urbanos en raíces de árboles de acacia amaría y nin. Hábitos: Parásito y saprófago, se desarrolla en forma solitaria o gregario. 
Observación: Cuando fresco es de textura corácea y cuando seco de textura leñosa. Olor agradable y de sabor amargo intenso.

Propiedades: Las investigaciones sobre las propiedades de G. lucium realizadas por Figlas (2007) coinciden con lo descrito por Masson (2003), en su obra "Vademécum de Prescripción" donde señalan que Ganoderma lucicum como antitumoral, anticancerígeno, inhibición de la agregación plaquetaria en vasos sanguíneos, antihipertención, Anti - VIH, Efecto Hipoglucémicos, inmunomoduladeros e inmunoterapeuticas, efectos anti - ateroscleróticos e hipo - lipidemicos, antiinflamatoria, actividad antioxidante, hepatoproctora, anti bacteriana y viral, anti fungica, antihipocolesterolémica, antifibrotica, protección por daños inducidos por radiación, entro otras.

Parte utilizada: Cuerpo fructífero

Principales constituyentes: Abundantes polisacáridos (45\%): $\beta$-D Glucano, Arabinogalactana; Ganoderana A, B y C. Triterpenos: ácidos ganodéricos A, B, C, F, H, K, M, R, F e Y; ganodermadiol, derivados del ácido lanostánico. Esteroides: ganodesterona. Ácidos grasos insaturados oleicos. Trasas de Alcaloides. Protidos Ling Zhi 8; glucoproteninas (lectina). Minerales: Germanio y calcio.

Acción farmacológica: sus polisacáridos de alto peso molecular, presenta invitro una acción inmuno estimulante, antitumoral (potencia la producción de Citocina por los macrofamos y linfocitos $\mathrm{T}$, y aumenta los niveles de interleucina IL-1 $\beta$, IL-2, IL-6, factor de necrosis tumoral $\alpha$ - y la liberación de interferon $\gamma$ ) anti viral (especialmente de forma preventiva), antinociceptiva e hipoglucemiante (véase efectos secundarios y precauciones). Los triterpenos son responsables de su acción anti inflamatoria, hipolipemiante (reduce los niveles de colesterol y triglicéridos), antihipertenciva y hepatoprotectora (acción reforzada por la ganodesterona): se ha comprobado que el Reishi produce un efecto antifibrótico sobre el hígado (rebaja el contenido de colágeno hepático, normaliza la estructura hepática alterada y reduce los niveles de aspartato transaminasa (AST), alinina transaminasa (ALT), GOT, lactodeshidrogenasa (LDH), fosfatasas alcalinas y Bilirubina total. Antihistaminico, por la acción de los ácido ganodericos y oleicos. Además se ha descrito un efecto anti agregante plaquetario y relajante muscular.

Indicaciones: Hepatitis aguda y crónica, Cirrosis hepática. Coadyuvante en la prevención y tratamiento de procesos oncológicos, hipertensión arterial, hiperlipemia, arterioesclerosis, prevención de trombo embolismo, diabetes. 
También se utiliza en el tratamiento de fondo de procesos alérgicos, inflamaciones ostioarticulares, mialgias, contracturas musculares e inmunodeficiencia inducida por abusos de opiáceos.

Efectos secundarios: inicialmente se puede producir una descompensación en los niveles de glucosa, que suele normalizar con el cabo de una semana.

Precauciones: Cuando se prescriba a pacientes con diabetes, el médico deberá controlar la glucemia para ajustar, si es necesario, las dosis de insulina o los antidiabéticos orales.

Cuando se prescriba a pacientes con dispepsia, recomendamos su administración postprandial, asociados a tisanas demulcentes (ejemplos, malvaviscos, malva o manzanilla).

Posología: De 3 a 9 gramos día, el efecto analgésico en neuralgia pos herpéticas se ha demostrado con 36-72 gramos por días.

\section{Ganoderma applanatum (Pers) Pat.}

Distribución: Puede encontrarse en los bosques, zonas urbanas y rurales de Managua, Carazo, Masaya y Matagalpa. Altura: Desde los 350 msnm hasta 600 msnm. Estacionalidad: De Finales de Mayo a Enero.

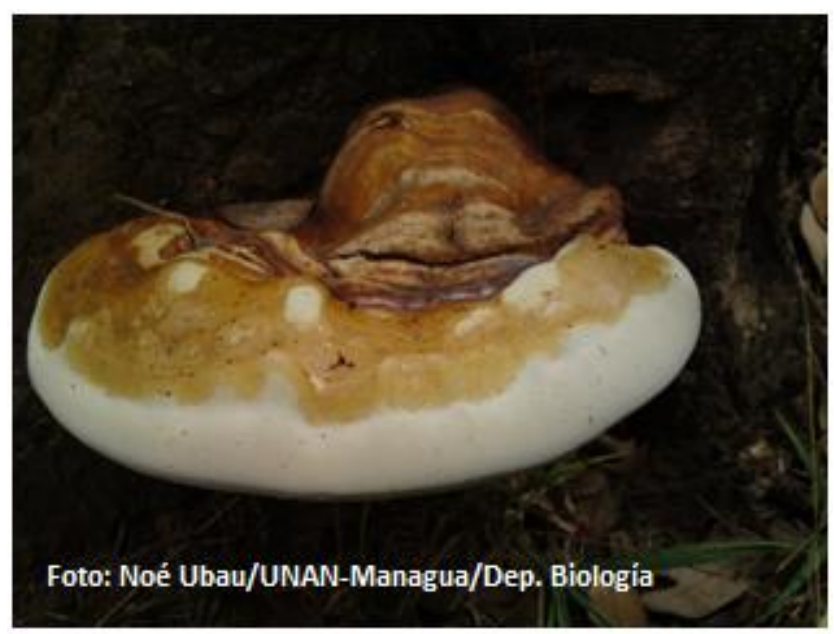

Figura 3. Ganoderma applanatum (Pers) Pat.

Descripción: Cuerpo fructífero en forma de abanico, de color marrón grisáceo a amarillo tenue; Píleo de $6.0 \mathrm{~cm}$ a $28.0 \mathrm{~cm}$ de ancho y de 3.4 $\mathrm{cm}$ a $16.0 \mathrm{~cm}$ de largo, de cutis seroso, quebradizo, con zonaciones irregulares, margen blanco; Himenóforo color blanco, formado por tubos de $0.3 \mathrm{~cm}$ a $0.9 \mathrm{~cm}$ de largo; Contexto color marrón oscuro de $1.0 \mathrm{~cm}$ a $5.0 \mathrm{~cm}$ de espesor; siempre sésil. Reproducción: Por esporas.

Esporada: Color marrón oscuro

Hábitos: Suele desarrollarse en forma parásita en árboles de acacia, entre $0.5 \mathrm{~m}$ a $6.0 \mathrm{~m}$ sobre el nivel del suelo, también puede encontrarse en tocones de árboles recién cortados.

Observación: De olor agradable y sabor amargo suave amargo.

Propiedades: Tiene propiedades anti-Cancerígena (InBio CR.). 
Nota: El acceso a investigaciones sobre la especie Ganoderma applanatum, se encuentran limitadas, debido que la bibliografía referida a estudios fitoquímico y bromatológicas de esta especie cuentan con un valor monetario que no está al alcance del investigador.

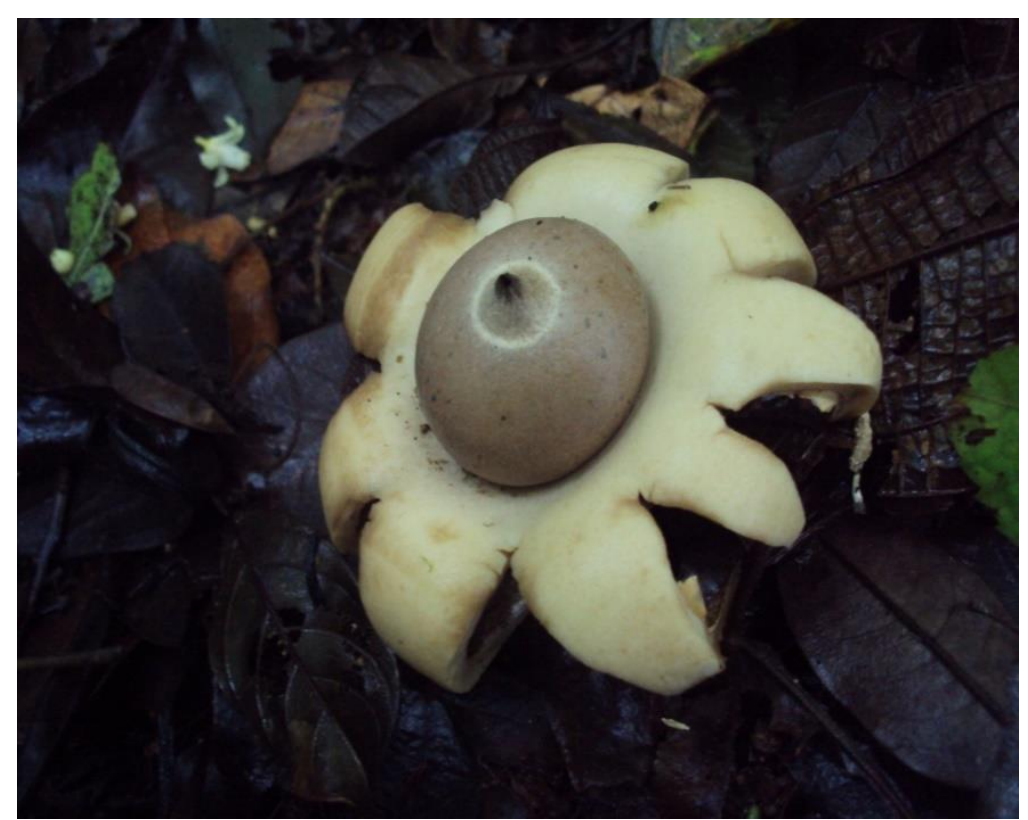

Figura 4. Geastrum triplex Jungh en estado natural

\section{Geastrum triplex Jungh.}

Distribución: En los departamentos de Carazo, Managua, Masaya y Matagalpa. Estacionalidad: Desde Mayo a Diciembre. Altura: Entre $400 \mathrm{msnm}$ a $1450 \mathrm{msnm}$.

\section{Descripción:}

Cuerpo

fructífero globoso esférico cuando juvenile y en estrella cuando maduro, entre 6 y 9 puntas, sésil, de color beige a grisáceo; tamaño de $3.5 \mathrm{~cm}$ a 11.0

cm de diámetro; Centro globoso color marrón, llamado endoperidio, de $2.5 \mathrm{~cm}$ de diámetro, zona apical provisto de un peristoma rodeado por una oriol blancuzca; Contexto, color blanco cuando joven y Marrón oscuro y polvoriento cuando maduro. Reproducción: Por esporas. Esporada: Marrón

Hábitos: Humícola. Habitad: En pendientes pronunciadas entre $45^{\circ}$ y $60^{\circ}$, generalmente después de las lluvias en los canales de escorrentías.

Propiedades: El Instituto de Biodiversidad de Costa Rica lo describe como una especie que puede ser utilizada como tónico para la garganta e hígado. 


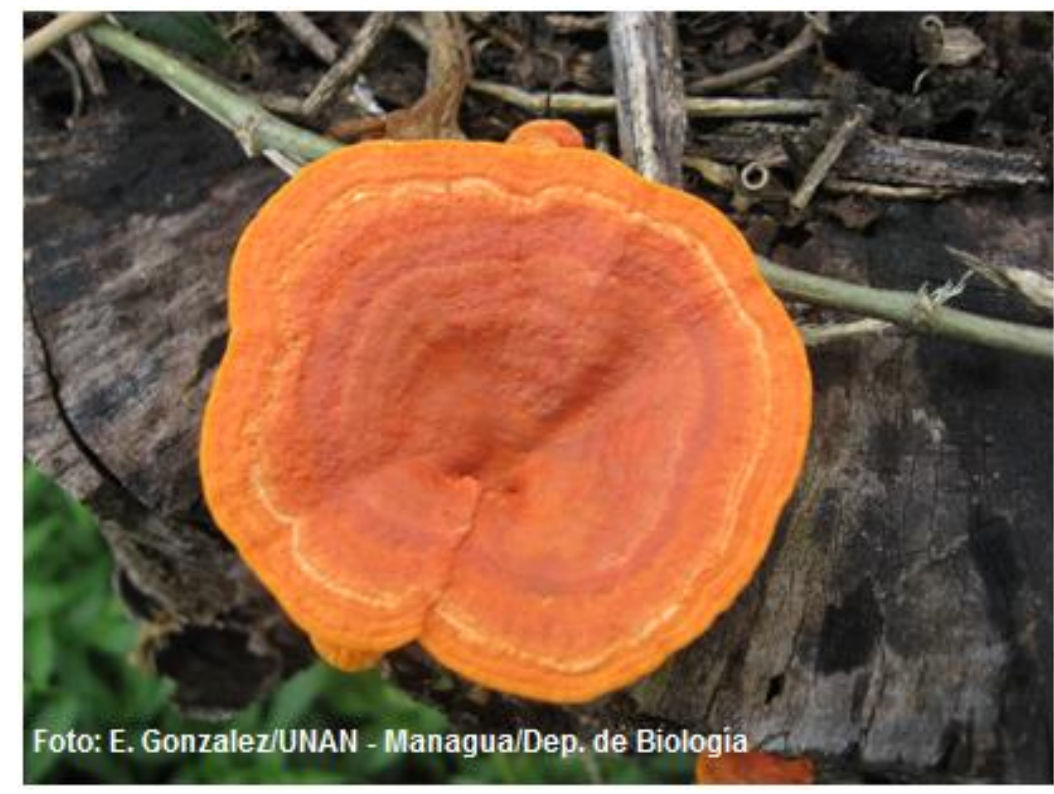

Figura 5. Pycnoporus sanguineus en estado natural
Pycnoporus sanguineus (L.:Fr)

Murrill.

Distribución: Común en zonas intervenida, muy intervenida $\mathrm{y}$ bosque seco. En zonas rurales y ciudad. Encontrándose en toda la vertiente del pacífico desde Rivas hasta Chinandega y región central desde Rio San Juan hasta Jinotega. Altura: desde 16 msnm hasta 400 msnm. Estacionalidad: Durante todo el año. En zonas cercanas al mar el cuerpo fructífero se

decolora adquiriendo color blanco.

Descripción: Cuerpo fructífero en forma de abanico u oreja, Cecil, de $1.5 \mathrm{~cm}$ a $8.0 \mathrm{~cm}$ de largo y de $3.4 \mathrm{~cm}$ a $10.0 \mathrm{~cm}$ de ancho, a veces circular. Cutis velutinoso a veces rugosa, de color rojonaranja brillante cuando fresco y anaranjado rojizo cuando seco; Himenóforo formado por poros naranja - rojizo intenso. Esporada no anotada. Reproducción: Por esporas. Esporada: No anotada.

Hábitos: Saprofago, suele desarrollarse sobre madera en descomposición, en zonas rurales se encuentra sobre los cercos y en los bosques en ramas secas de árboles vivos y en troncos secos.

Propiedades: El Instituto de Biodiversidad de Costa Rica, en base a los estudios realizados por Pérez Silva, Aguirre Acosta, y Pérez Amador (1988), describen a P. sanguineus como una especie medicinal que al igual que algunas tribus de Latino América que describieron sus propiedades desde hace ya mucho tiempo, la forma de usarlo era pulverizando el cuerpo fructífero y aplicaban sobre las heridas para coagular la sangre (hemostático) y también para eliminar verrugas en la piel. En África lo utilizan en infusiones (en té) para eliminar paracitos intestinales, problemas de la menopausia y otras enfermedades del vientre. En Asia se usa para bajar la fiebre, contrarrestar problemas e reumatismo, artritis, gota, etc. Los cuerpos fructíferos de esta especie se utilizan para aplicar sobre heridas, ya que detiene el sangrado y previene infecciones. Además activa la circulación sanguínea y se ha demostrado que tiene actividad antitumoral. 


\section{Trametes versicolor (L.: Fr) Pilát}

Distribución: Se encuentra comúnmente en los bosques secos y zonas con intervención humana en la región centro y sur pacífico y en toda la región central. Altura: 30 msnm a 600 msnm. Estacionalidad: Perenne todo el año; en los meses de mucha lluvia tienden a sobre satura el cuerpo fructífero y desaparecer hasta que las condiciones se normalicen.

Descripción: Cuerpo fructífero en forma de oreja o abanico, sésil, de $3.0 \mathrm{~cm}$ a $13.4 \mathrm{~cm}$ de

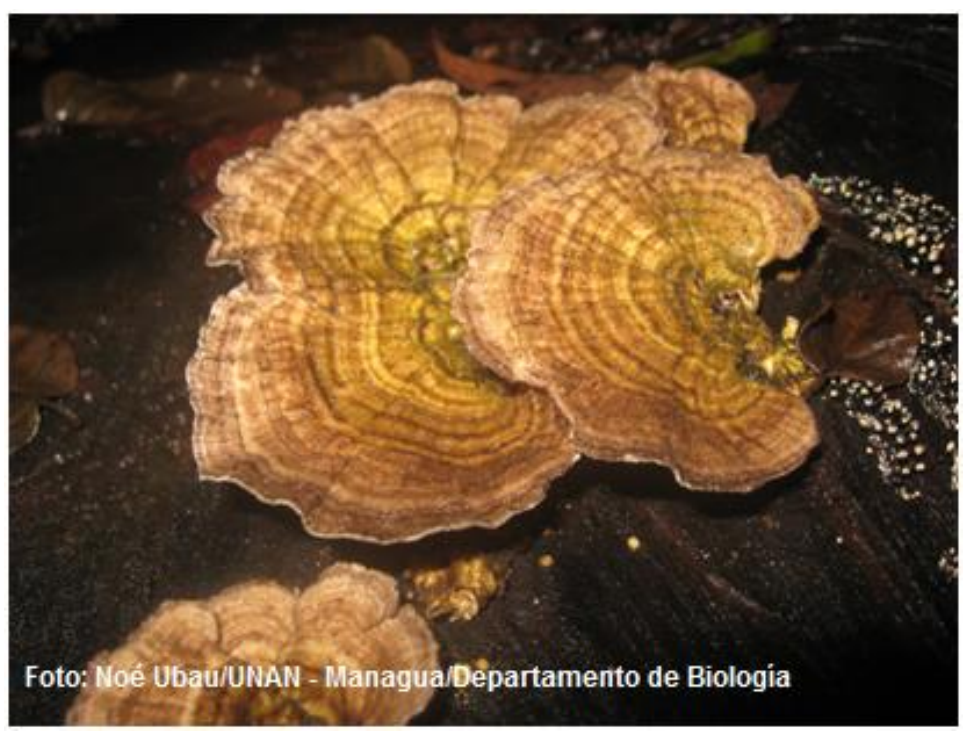
ancho y de $2.3 \mathrm{~cm}$ a $8.0 \mathrm{~cm}$ de largo. Cutis rugoso a veces aterciopelado, presenta zonaciones de colores, marrones, verdes rojizos, beige y grises; Textura corácea cuando fresco, cuando seco adquiere textura leñosa; Himenóforo formado por poros geométricos o no, de color beigegrisáceos. Reproducción: Por esporas. Esporada: No anotada.

Hábitat: suele desarrollándose sobre madera en descomposición en el bosque en troncos caídos y Figura 6. Trametes versicolor cercas.

Propiedades: En algunos países se conoce a T. versicolor como tóxico, pero este mito fue desmentido por el holandés Jan - Willem Spaagares, en estudios realizados en los laboratorios de Groen Agro Control, y concluye en su trabajo no existe riesgo de intoxicación por la ingestión de Trametes versicolor.

Utilizado en Inglaterra en el tratamiento del cáncer por la disminución de telomerasa y aumento de la función inmune que se desplaza hacia respuestas inmunitaria mediada por células TH1, que es la respuesta antitumoral más eficaz. También presentan mayor concentraciones significativas del polisacárido PSP, mayor que otras preparaciones de hongos, concretamente las biomasa equivalentes de Grifola frondosa((Maitake), Ganoderma lucidum (Reishi) y Cordicep sinensis. Esta forma de Biomasa de T. versicolor, también tiene significativamente mayor actividad de peroxisa que las Biomasa equivalentes de Grifola frondosa y Ganoderma lucidum concretamente. En china es utilizado como coadyuvante clínico del cáncer (Kenyon et al. 2003). 
Mohammed y Lawrence (en base a los estudios realizados por Kenyon, 2003), uso terapéutico en pacientes con Colitis Ulcerosa y Síndrome de Crohn, donde se demuestra que con el tratamiento de $T$. versicolor, en pacientes con colitis ulcerosa, al cabo de 4 cuatro semanas los síntomas desaparecieron y en el caso del síndrome de Crohn al cabo de 28 días con el tratamiento hubo una doble disminución de los dolores y fatiga.

Ferro y Boaventura en 2002 trataron con suplementode Trametes versicolor, a una paciente con cáncer de mama para apoyar el sistema inmunológico, el cual presento datos curiosos, la paciente presentó cambios el sistema inmunitario positivos y disminución de fatiga común en pacientes con cáncer.

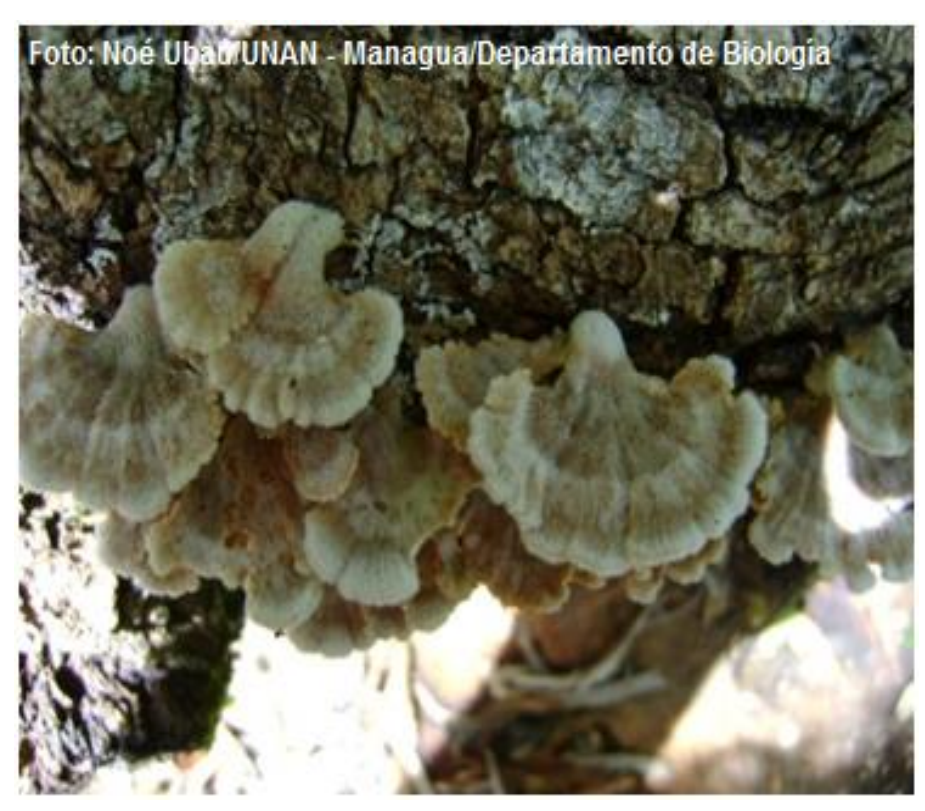

\section{Schizophyllum commune Fr.}

Distribución: Se encuentra por toda la vertiente del pacífico y región central (Anexo 4). Estacionalidad: Todo el año. Altura: Desde los 30 msnma hasta 600 msnm.

Descripción: Cuerpo fructífero en forma de espátula, Píleo de $1,5 \mathrm{~cm}$ a $5,3 \mathrm{~cm}$ de largo y de $0,7 \mathrm{~cm}$ a $4,3 \mathrm{~cm}$ de ancho, semicircular; superficie cubierta por vellosidades finas aterciopelada, con líneas

Figura 7.Schizophyllum de color blanco gris-rosáceo; zona fértil formado por laminas decurrentes y laminillas de color beige - grisáceo, con vellosidades suaves y finos en el borde. Con o sin estípite, siempre marginal, adherido lateralmente al sustrato. Reproducción: Por medio de esporas. Esporada: Blanca

Hábitos: Saprofrago, árboles muertos y madera en descomposición. Habitad: Bosques secos, lluviosos y pre montano, también en áreas intervenidas sobre postes de cercos y leña.

Propiedades: En la medicina tradicional China, Schyzophyllum commune se utiliza en forma de infusiones contra la leucorrea. Produce el polisacárido inmunoestimulante schyzophylano o sonifilano ((1-3) - $\beta$-D-glucano con ramificaciones (1-6)- $\beta$-glucosil), el cual se utiliza ampliamente para el tratamiento del cáncer cervical (O. Morales \& R. Flores et al. 2008). El Instituto de 
Biodiversidad de Costa Rica le atribuye también propiedades antitumorales (Sarcomas y Carcomas), de uso en pacientes con cáncer gastrointestinal y quimioterapia.

\section{CONCLUSIONES}

En Nicaragua se conocen hasta el momento 7 especies de hongos medicinales de alto valor nutricional y medicinal de gran potencial económico.

Las siete especies de hongos pertenecen a los Basidiomycetes, agrupados en cinco órdenes y cinco familias distintas, Auriculariales - Auriculariaceae, Ganodermatales - Ganodermataceae, Geastrales - Geastraceae, Poriales - Coriolaceae y Schizophyllales - Schizophyllaceae, y seis géneros respectivamente, Auricularia, Ganoderma, Ceastrum, Pycnoporus, Trametes y Schizophyllum.

Las especies de hongos más comunes de encontrar con una amplia distribución son Auricularia auricula y Schizophyllum commune.

El 65\% de estas especies, es decir, cuatro de siete especies se encuentran en el Recinto Universitario Rubén Darío de la UNAN - Managua; Ganoderma lucidum, Ganoderma applanatum, Pycnoporus sanguineus y Schizophyllum commune.

Las especies Auricularia auricula, Ganoderma lucidum, Ganoderma applanatum y Trametes versicolor son las de mayor importancia debido a la presencia de polisacáridos y polipéptidos que coadyuvan en el tratamiento y prevención de cáncer, mitigación de los efectos de fatiga y deficiencia inmunitaria producidos por la quimioterapia y radioterapia, tratamiento a pacientes con VIH - SIDA, enfermedades cardiacas, circulatorias y hepáticas.

Schizophyllum commune, se le atribuyen propiedades antitumorales por la el contenido de polisacáridos que actúan en el fortalecimiento del sistema inmunitario.

Geastrum triplex, de esta especie se conoce poco, debido al irregularidad o en la frecuencia que es encontrado, pero se le atribuyen propiedades como tónico para la garganta y actividad hepatoprotectora.

Las especies de hongos medicinales son de gran valor económico, social, nutricional y científico, abre nuevas brechas en trabajos de investigación y deja al descubierto la necesidad de la integración multidisciplinaria.

\section{REFERENCIAS}

Figlas, D. (2007). Propiedades del Hongo Reishi (Ganoderma lucidum)/ Laboratorio de Biotecnología de Hongos Comestibles y Medicinales, Monografía. CERZOS (CONICET)/ Argentina/Pág. $10-20$.

Kenyon, J. (2003). Estudio de Observación no Controlado del uso de la suplementación con Coriolus versicolor en 30 pasientes con Cáncer/Mycology News - Versión en Español/ Inglaterra. Pág. $2-5$. 
Masson (2003). Fito Terapia/Vademécum de Prescripción/Cuarta Edición/editores B. VanaclochaS. Cañigueral. Barcelona

Spaargaren, J.W. (2004). Trametes versicolor/Groen Agro Control/Holanda.

Pérez Silva, E., Aguirre Acosta, E., \& Pérez Amador, C. (1988). Aspectos sobre el uso y la distribución de Pycnoporus sanguineus (Polyporaceae) en México. Rev. mex. micol, 4, 137-44. 